\title{
POLA PERESEPAN OBAT ANTIMALARIA DI RSUD DOK II JAYAPURA PADA TAHUN 2016
}

\author{
Nurwulan Adi Ismaya \\ Sekolah Tinggi Ilmu Kesehatan Kharisma Persada \\ Tangerang Selatan, 15417 \\ E-mail: wulan.ismaya@gmail.com
}

\begin{abstract}
ABSTRAK
Latar Belakang: Malaria tergolong sebagai salah satu penyakit menular yang sangat berbahaya dapat menyebabkan kematian. Di Provinsi Papua, malaria merupakan penyakit endemik karena merupakan daerah beriklim tropis sehingga rentan dengan penyakit ini. Tujuan :Penelitian ini bertujuan untuk mengetahui pola peresepan antimalaria pada pasien di Instalasi Rawat Jalan RSUD Dok II Jayapura tahun 2016. Metodologi Penelitian: Jenis penelitian yang digunakan adalah Deskriptif dengan pendekatan secara Retrospektif. Hasil: Berdasarkan hasil penelitian ini adalah berdasarkan usia yang tertinggi adalah 26-35 tahun (28,9\%), berdasarkan jenis kelamin yang tertinggi dalah laki-laki yaitu 203 (53,42\%), berdasarkan diagnosa yang paling tertinggi adalah plasmodium falciparum 220 (57,89\%), berdasarkan golongan obat yang tertinggi adalah NON ACT sebanyak 335 (39,92\%), berdasarkan jumlah obat yang tertinggi adalah primakuin 335 (88,15\%), berdasarkan bentuk sediaan yang tertinggi adalah tablet $617(73,53 \%)$, berdasarkan dosis yang teringgi adalah primakuin $15 \mathrm{mg}$ dengan jumlah 335 (35,68\%). Kesimpulan: Penggunaan obat malaria berdasarkan jumlah obat paling banyak adalah Primakuin. Berdasarkan bentuk sediaan paling banyak adalah Tablet. Pola peresepan antimalaria yang paling banyak di gunakan di Instalasi Rawat Jalan RSUD dok II Jayapura adalah berdasarkan golongan obat yang tertinggi adalah NON ACT, berdasarkan dosis yang teringgi adalah primakuin $15 \mathrm{mg}$.
\end{abstract}

Kata Kunci : Malaria, Obat Malaria, Pola Peresepan

\begin{abstract}
Background: Malaria is classified as one of the most dangerous infectious diseases that can cause death. In the province of Papua, malaria is an endemic disease because it is a tropical climates and therefore susceptible to this disease. Objective: This study aims to determine the pattern of antimalarial prescription in patients in the Outpatient Installation of RSUD Dok II Jayapura 2016.Research Methodology: The type of research used is Descriptive with Retrospective approach. Results: Based on the results of this study, the highest age was 26-35 years old (28.9\%), based on the highest sex of males ie 203 (53.42\%), based on the highest diagnoses were plasmodium falciparum 220 (57,89\%), based on the highest drug class was NON ACT 335 (39,92\%), based on the highest amount of drug is 335 primaquine (88,15\%), based on highest dosage form is tablet 617 (73, 53\%), based on the highest dose is primaquine $15 \mathrm{mg}$ with the amount of 335 (35,68\%).

Conclusion: The use of antimalarial drugs based on the most amount of drugs is Primaquin. Based on the most dosage form is Tablet. The most prevalent antimalarial prescribing pattern used in the Outpatient Installation of RSUD dok II Jayapura was the highest drug class was NON ACT, based on the highest number of drugs was primaquine, based on the highest dose was primaquine $15 \mathrm{mg}$.
\end{abstract}

Keywords : Malarial, Antimalarial drugs, Prescribing pattern

\section{LATAR BELAKANG}

Malaria masih merupakan salah

satu masalah kesehatan masyarakat yang dapat menyebabkan kematian

terutama pada kelompok risiko tinggi, 
yaitu bayi, anak balita, dan ibu hamil.

Selain itu, malaria secara langsung menyebabkan anemia dan dapat menurunkan produktivitas kerja (Paul, 2006).

Pada tahun 2010 di Indonesia terdapat $65 \%$ kabupaten endemis dimana hanya sekitar $45 \%$ penduduk di kabupaten tersebut berisiko tertular malaria. Berdasarkan hasil survei komunitas selama $2007 \quad-2010$, prevalensi malaria di Indonesia menurun dari 1,39 \% (Riskesdas 2007) menjadi 0,6\% (Riskesdas 2010). Sementara itu berdasarkan laporan yang diterima selama tahun 2000-2009, angka kesakitan malaria cenderung menurun yaitu sebesar 3,62 per 1.000 penduduk pada tahun 2000 menjadi 1,85 per 1.000 penduduk pada tahun 2009 dan 1,96 tahun 2010. Sementara itu, tingkat kematian akibat malaria mencapai 1,3\% (Anonim, 2013).

Walaupun telah terjadi penurunan Annual Parasite Incidence (API) secara nasional, di daerah dengan kasus malaria tinggi angka API masih sangat tinggi dibandingkan angka nasional, sedangkan pada daerah dengan kasus malaria yang rendah sering terjadi kejadian Luar Biasa (KLB) sebagai akibat adanya kasus impor. Pada tahun 2011 jumlah kematian malaria yang dilaporkan adalah 388 kasus. Prevalensi nasional malaria berdasarkan hasil Riskesdas tahun 2010 adalah 0,6\% dimana provinsi dengan API di atas angka rata-rata nasional adalah Nusa Tenggara Barat, Maluku, Maluku Utara, Kalimantan Tengah, Bangka Belitung, Kepulauan Riau, Bengkulu, Jambi, Sulawesi Tengah, Gorontalo, dan Aceh. Tingkat prevalensi tertinggi ditemukan di wilayah timur Indonesia, yaitu di Papua Barat (10,6\%), Papua (10,1\%) dan Nusa Tenggara Timur (4,4\%). (Riskesdas, 2013)

Upaya untuk menekan angka kesakitan dan kematian dilakukan melalui program pemberantasan malaria yang kegiatannya antara lain meliputi diagnosis dini, pengobatan cepat dan tepat, serta surveilans dan pengendalian vektor dalam hal pendidikan masyarakat dan pengertian tentang kesehatan lingkungan, yang kesemuanya ditujukan untuk memutus mata rantai penularan malaria. Kasus resistensi parasit malaria terhadap klorokuin ditemukan pertama kali di Kalimantan Timur pada tahun 1973 untuk P.falcifarum, dan tahun 1991 untuk $P$. vivax di Nias. Sejak tahun 1990,kasus resistensi tersebut dilaporkan makin meluas di seluruh provinsidi Indonesia. Selain itu, dilaporkan juga adanya resistensi terhadapSulfadoksin-Pirimethamin (SP) 
di beberapa tempat di Indonesia. Keadaan ini dapat meningkatkan morbiditas dan mortalitas penyakit malaria. Oleh sebab itu, untuk menanggulangi masalah resistensi tersebut (multiple drugs resistance) dan adanya obat anti malaria baruyang lebih paten, maka pemerintah telah merekomendasikan obatpilihan pengganti klorokuin dan SP, yaitu kombinasi derivate artemisinin dengan obat anti malaria lainnya yang biasa disebutdengan

Artemisinin

Combination Therapy (ACT) (Depkes RI, 2009).

Pengobatan atau penatalaksanaan malaria membutuhkan waktu yang lama, malaria dapat dicegah dengan gaya hidup sehat dan mengendalikan fakor risiko seperti mengatur pola makan, olahraga yang teratur, menghindari merokok dan minuman beralkohol. Pelayanan resep obat antimalaria di Instalasi rawat jalan
RSUD Dok II Jayapura sering di jumpai adanya keterlambatan pengadaan obat ke gudang farmasi dan mengakibakan resep yang terlalu banyak sehingga sering kali terjadinya keterlambatan pemberian obat yang pada akhirnya akan menyebabkan pasien menunggu lebih lama. Oleh karena itu saya tertarik untuk meneliti “ Pola Peresepan Obat Antimalaria di RSUD Dok II Jayapura pada tahun 2016".

\section{METODE}

Jenis penelitian yang digunakan adalah Deskriptif dengan pendekatan secara Retrospektif. Populasi salam penelitian ini adalah selurup resep di Instalasi rawat jalan RSUD Dok II Jayapura. Berdasarkan data tahun 2016 (januari-desember 2016) ada 7708 resep di rawat jalan. Sampel pada penelitin ini sejumlah 380 resep dengan menggunakan sistemic random sampling.

\section{HASIL}

\section{Berdasarkan Golongan Obat}

Tabel 1. Distribusi Pasien Malaria berdasarkan Golongan Obat

\begin{tabular}{ccccc}
\hline No & Golongan & Nama Obat & Jumlah & $\%$ \\
\hline 1 & ACT & Darplex & 282 & $60,07 \%$ \\
& & Artesunat & 222 & \\
\hline 2 & NON ACT & primakuin & 335 & $39,92 \%$ \\
\hline $\mathbf{3}$ & Total & & $\mathbf{8 3 9}$ & $\mathbf{1 0 0 \%}$ \\
\hline
\end{tabular}


Berdasarkan hasil penelitian di RSUD Dok II Jayapura yang dilihat dari penggunaan golongan obat antimalaria tertinggi yaitu golongan NON ACT dengan nama obat Primakuin sebayak $335(39,92 \%)$.

\section{Berdasarkan Jumlah Obat}

Tabel 2. Distribusi Pasien Malaria berdasarkan Jumlah Obat

\begin{tabular}{cccc}
\hline No & Nama Obat & Jumlah & $\%$ \\
\hline 1 & Primakuin & 335 & $88,15 \%$ \\
\hline 2 & Darplex & 282 & $74,21 \%$ \\
\hline 3 & Artesunat & 222 & $58,42 \%$ \\
\hline $\mathbf{4}$ & Total & $\mathbf{8 3 9}$ & $\mathbf{1 0 0 \%}$ \\
\hline
\end{tabular}

Berdasarkan hasil penelitian di RSUD Dok II Jayapura untuk pasien malaria paling banyak menggunakan Primakuin sebanyak 335 (88,15\%).

\section{Berdasarkan Bentuk Sediaan.}

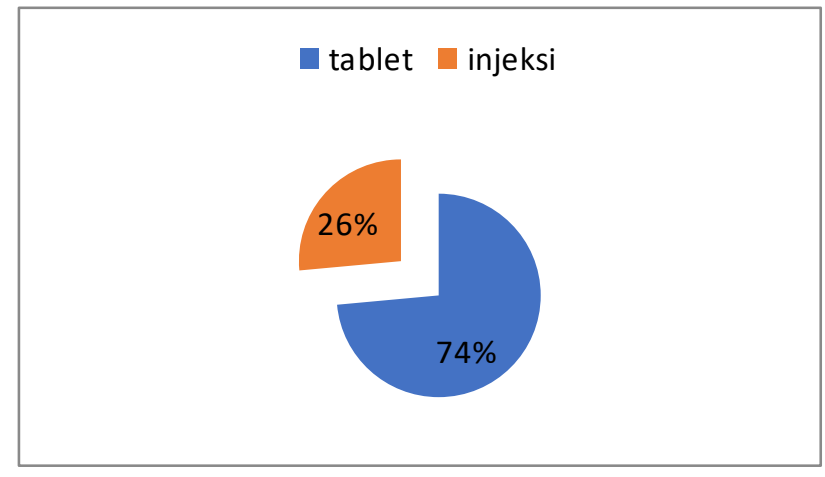

\section{Gambar 1. Distribusi Pasien Malaria Berdasarkan Bentuk Sediaan}

Berdasarkan hasil penelitian di RSUD Dok II Jayapura untuk pasien malaria paling banyak menggunakan sediaan Tablet sebanyak $617(73,53 \%)$ ini ada 2 jenis obat yaitu Primakuin dan Darplex.

\section{Berdasarkan Dosis}

Tabel III.4

Distribusi Pasien Malaria Berdasarkan Dosis

\begin{tabular}{ccccc}
\hline No & Obat & Dosis & Jumlah & $\%$ \\
\hline 1 & Primakuin & $15 \mathrm{mg}$ & 335 & 35,68 \\
\hline 2 & Darplex & $360 \mathrm{mg}$ & 282 & 30,04 \\
\hline 3 & Artesunat & $5 \mathrm{ml}$ & 222 & 23,65 \\
\hline
\end{tabular}




\begin{tabular}{llcc}
\hline 4 & Total & 839 & 100
\end{tabular}

Berdasarkan hasil penelitian di RSUD Dok II Jayapura untuk pasien malaria paling banyak menggunakan Dosis dengan urtutan yang tertinggi adalah Primakuin yaitu $15 \mathrm{mg}$ dengan jumlah 335 (35,68\%).

\section{DISKUSI}

\section{Berdasarkan Usia}

Berdasarkan hasil penelitian yang dilihat dari presentase usia pasien penderita malaria terbanyak berdasarkan kelompok kriteria umur 26-35 tahun $(28,9 \%)$ dan sisanya $17-25$ tahun $(27,1 \%), 36-45$ tahun (16,5\%), 5-11 tahun (7,63\%), 0-5 tahun (7,10\%), 12-16 tahun(5,78\%), 46-55 tahun $(3,68 \%), 56-65$ tahun $(2,63 \%), 65-$ sampai atas $(0,52 \%)$.

Dari jumlah presentase usia yang dominan terkena penyakit malaria adalah 26-35 tahun. Hasil ini sesuai dengan pustaka yang menyatakan bahwa di usia tersebut memiliki tugas dan tanggung jawab yang lebih berat, karena usia tersebut rata-rata orang yang sudah bekerja di luar rumah dan bandingkan dengan usia $65 \mathrm{ke}$ atas dimana usia tersebut sudah memasuki kategori usia lanjut (Harijanto P.N, Nugroho A, Gunawan CA).

\section{Berdasarkan Jenis Kelamin}

Berdasarkan karakteristik jenis kelamin, penderita malaria terbanyak adalah berjenis kelamin laki-lakiyaitu 203 $(53,42 \%)$ dan perempuan sebanyak 177
(46,57\%). Pada penelitian ini digunakan data jenis kelamin laki-laki dan perempuan untuk mengetahui pengaruh jenis kelamin terhadap penyakit malaria. Penelitian ini menunjukkan jumlah dan persentase pasien malaria di Instalasi Rawat Jalan RSUD dok II Jayapura tahun 2016. Belum diketahui dan belum adanya pustaka mengenai mengapa laki-laki lebih banyak yang terkena malaria dibandingkan dengan perempuan.

\section{Beradasarkan Diagnosa}

Berdasarkan penelitian dengan diagnosa yang paling tertinggi adalah Plasmodium Falcifarum $220 \quad$ (57,89\%). Karena kondisi lingkungan rumah yang tidak bersih atau tidak terawat sehinga pola makan dan pola hidup tidak terkendalikan sehingga daya tahan tubuh menurun dan disitulah terjangkitnya penyakit malaria dan mengakibatkan kematian khusunya daerah Jayapura masih banyak terdapat hutanhutan yang luas (Widjaja.Y).

\section{Berdasarkan Golongan Obat}

Berdasarkan hasil penelitian di RSUD Dok II Jayapura yang dilihat dari 
penggunaan golongan obat antimalaria terbanyak yaitu golongan NON ACT dengan nama obat Primakuin sebayak 335 (39,92\%). Kemudian golongan ACT dengan nama obat Darplex sebanyak 282 $(33,61 \%)$, dan Artesunat injeksi sebanyak $222(26,46 \%)$ sesuai karena golongan NONI. ACT obat anti malaria yang efektif membunuh gametosit sehingga obat tersebut wajib diberikan untuk setiap pasien malaria. Primakuin juga mampu memutus rantai transmisi parasit dan mencegah penyebaran resistensi (Abay SM).

\section{Berdasarkan Jumlah Obat}

Berdasarkan hasil penelitian di RSUD Dok II Jayapura untuk pasien malaria paling banyak menggunakan Primakuin sebanyak 335 (88,15\%), Darplex 282 $(74,21 \%)$, dan Artesunat 222 (58,42\%). Hasil ini sesuai dengan pustaka yang menyatakan bahwa Primakuin sebagai obat yang menghambat gametosit dan sebagai anti relaps pada penyakit malaria (Kemenkes No.5 tahun 2013).

II. Berdasarkan Bentuk Sediaan.

Berdasarkan hasil penelitian di RSUD Dok II Jayapura untuk pasien malaria paling banyak menggunakan sediaan Tablet sebanyak $617(73,53 \%)$ ini ada 2 jenis obat yaitu Primakuin dan Darplex. Sedangkan sediaan Injeksi yaitu Artesunat sebanyak 222 (26,46\%). Hasil ini sesuai dengan pustaka yang menyatakan bahwa sediaan
Tablet lebih banyak daripada sediaan Injeksi, karena pasien rawat jalan lebih sering mendapatkan obat sediaan tablet di bandingkan injeksi yang kebanyakan di pakai untuk pasien rawat inap (Kemenkes No.5 tahun 2013).

Berdasarkan Dosis

Berdasarkan hasil penelitian di RSUD Dok II Jayapura untuk pasien malaria paling banyak menggunakan dosis yang paling sering digunakan adalah dengan urutan yang tertinggi adalah Primakuin yaitu $15 \mathrm{mg}$ dengan jumlah 335 (35,68\%). Menurut (Abay SM.) bahwa primakiun dapat menyebabkan tingginya frekuensi gametositemia. Waktu pemberian obat yang optimal merupakan salah satu faktor yang berperan penting. Sebuah meta analisis menyatakan bahwa pemberia nprimakuin yang terlalu dini hanya akan membasmi gametosit dewasa (stadium V) dan tidak mampu mencegah pertumbuhan gametosit muda (stadium I-IV) sehingga penularan masih akan terjadi dalam waktu 10 hari.

\section{KESIMPULAN}

Penggunaan obat malaria berdasarkan jumlah obat paling banyak adalah Primakuin. Berdasarkan bentuk sediaan paling banyak adalah Tablet. Pola peresepan antimalaria yang paling banyak di gunakan di Instalasi Rawat Jalan RSUD 
dok II Jayapura adalah berdasarkan golongan obat yang tertinggi adalah NON ACT, berdasarkan dosis yang teringgi adalah primakuin $15 \mathrm{mg}$.

\section{DAFTAR PUSTAKA}

Ditjen PP \& PL Depkes RI. Pedoman Penatalaksanaan Kasus Malaria di Indonesia.Jakarta: PP \& PL; 2012

Departemen kesehatan RI. Pedoman Tatalaksana Kasus Malaria di Indonesia Jakarta. 2009:1-56

Depkes RI. Penggunaan artemisin untuk atasi malaria di daerah yang Resisten klorokuin. $2004 . \quad$ dalam www.depkes.go.id Smart T. HIV/malaria.2004. Dalam: http://www.aidsmap.com/en/news

Dinkes Provinsi Papua: Profil Kesehatan Provinsi Papua Tahun 2014. Papua: Dinas Kesehatan Provinsi Papua; 2014

Abay SM. Blocking malaria transmission to anopheles using artemisinin derivatives and primaquine: a systematic review and meta--analysis. Abay Parasites \& Vectors. 2013;;6:278.

Anonim, 2013. Badan Layanan Umum RSUP Prof. Dr. R. D. Kandou Manado. http://rsupkandou.com/ Diakses tanggal 22 Maret 2013
Berrang., et al., 2008. A spatial analysis of individual- and neighborhood-level determinants of malaria incidencein adults, Ontario, Canada

Ditjen PP \& PL Depkes RI. Pedoman Penatalaksanaan Kasus Malaria di Indonesia.Jakarta: PP \& PL; 2012

DepkesRI. Buletin Epidemiologi Malaria di Indonesia. Kementerian Kesehatan

RI. Jakarta: Departemen Kesehatan Republik Indonesia; 2011

Departemen kesehatan RI. Pedoman Tatalaksana Kasus Malaria di Indonesia Jakarta. 2009:1-56

Depkes RI. Penggunaan artemisin untuk atasi malaria di daerah yang Resisten klorokuin. 2004. dalam www.depkes.go.id Smart T. HIV/malaria.2004. Dalam: http://www.aidsmap.com/en/news

Dinkes Provinsi Papua: Profil Kesehatan Provinsi Papua Tahun 2014. Papua: Dinas Kesehatan Provinsi Papua; 2014

Friaraiyatini., Keman S., Yudhastuti R., 2006. Pengaruh Lingkungan dan Perilaku Masyarakat Terhadap Kejadian Malaria di Kab. Barito Selatan Propinsi Kalimantan Tengah. Jurnal Kesehatan Lingkungan. 2:121128

Harijanto P.N, Nugroho A, Gunawan CA. Malaria dari Molekuler ke Klinis Edisi 2. Jakarta: EGC; 2010 
Permenkes RI NO.5 Tahun 2014 Tentang

Pedoman Tatalaksana Malaria Mentri

Kesehatan Republik Indonesia

Riset Kesehatan Dasar (Riskesdas) 2013

WHO.The Situation of Malaria in the world

J.Epid week, 1977

World Health Organization: World Malaria

Report 2012 Summary. Swizerland:

WHO; 2012

WidjajaY. Faktor Risiko Kejadian Malaria

di Desa Santu'un Kecamatan Muara

Uya Kabupaten Tabalong Provinsi

Kalimantan Selatan [Tesis].

Yogyakarta: Universitas Gadjah

Mada; 2011 
